\title{
Comparison of Three Energy-Saving Strategies Based on Models Established for In Situ Gas Thermal Remediation of Contaminated Soil
}

\author{
Haijing Zhang $\mathbb{D}^{1},{ }^{1}$ Xiang Zhang $\mathbb{D}^{1},{ }^{1}$ Yao Yin $\mathbb{D}^{1},{ }^{1}$ Gaojie Liu $\mathbb{D}^{2},{ }^{2}$ Yu Zhu $\mathbb{D}^{1},{ }^{1}$ Xuejun Tan $(\mathbb{D})$, \\ and Yuan Huang $\mathbb{1}^{3}$ \\ ${ }^{1}$ Shanghai Municipal Engineering Design Institute (Group) Co., Ltd., Shanghai 200092, China \\ ${ }^{2}$ School of Energy and Power Engineering, University of Shanghai for Science and Technology, Shanghai 200093, China \\ ${ }^{3}$ Institute of Environmental Pollution and Health, School of Environmental and Chemical Engineering, Shanghai University, \\ Shanghai 200444, China
}

Correspondence should be addressed to Yao Yin; yinyao@smedi.com

Received 2 November 2021; Accepted 27 December 2021; Published 17 January 2022

Academic Editor: Dongdong Ma

\begin{abstract}
Copyright (c) 2022 Haijing Zhang et al. This is an open access article distributed under the Creative Commons Attribution License, which permits unrestricted use, distribution, and reproduction in any medium, provided the original work is properly cited.
\end{abstract}

\begin{abstract}
Soil pollution has become an issue of concern with the development of industrialization. In situ gas thermal remediation is a suitable remediation technology for heavily organic contaminated soil, yet its high energy consumption limits the application. In this study, three energy-saving strategies, off-gas burn-back mode, heat-returning mode, and air-preheating mode, were proposed, and their natural gas consumption and energy utilization ratio were analysed. A mathematical model was established for the heat and mass transfer in unsaturated soil by employing conjugate heat transfer. The temperature of the soil and flue gas, and the concentration of components in the soil and off-gas were simulated, which indicated the thermal behavior of the contaminated soil and the timing for operation control. Models of burners were also developed under different energy-saving modes for energy analysis. By comparing the basic method, adopting the off-gas burn-back mode obtained an energy-saving effect of 3.37\%, which relied on the content and calorific value of the pollutant in the off-gas. Under combustion air-preheating ratios of 0.5 and 1.0, natural gas could only be saved by $13.56 \%$ and $18.88 \%$, respectively. In general, the most effective energy-saving measure was the heat-returning mode, by which $21.44 \%$ of natural gas could be saved when the reflux ratio of the flue gas was 0.5 .
\end{abstract}

\section{Introduction}

In situ gas thermal remediation (ISGTR) is a type of remediation technology with a high heating temperature, thorough remediation effect, short remediation period, and is suitable for heavily organic contaminated soil [1-3]. However, high energy consumption is the main factor that limits its popularity. ISGTR can raise the soil temperature to 750 to $800^{\circ} \mathrm{C}[4,5]$, but the energy utilization rate is relatively low, which is generally $30 \%$ to $60 \%$ [6]. During the remediation process, ISGTR ordinarily uses natural gas as an energy source. The heating gas produced by the combustion of natural gas flows into the heating wells, which are inserted vertically into the soil. After the heating gas heats the soil, the flue gas with a large amount of waste heat is discharged directly into the environment, and the off-gas which contains organic pollutants is extracted from the extraction well. The waste heat in flue gas has hardly been recovered and recycled in current projects, which is a huge waste from an energy-saving point of view. Meanwhile, remediation projects often consume a lot of power sources to treat the pollutants with a certain calorific value in the off-gas rather than utilizing their heat of combustion, which means the waste of massive energy in the off-gas.

Many energy-saving strategies for ex situ thermal desorption have been studied and applied in recent years $[7,8]$. Ma et al. [9] reported that the addition of citric acid during thermal treatment could shorten the remediation time. Marcet et al. [10] found that microbial remediation coupled with 
thermal desorption technology could effectively reduce energy consumption. However, at this stage, research related to energy-saving methods for in situ thermal desorption is still insufficient. Among the limited cases, Li et al. [2] summarized three energy-saving methods: batch treatment, coupling with in situ chemical oxidation, and installing a heat-tracing extraction pipeline. Li et al. [11] presented three energy-saving strategies in ISGTR (variable-condition mode, heat-returning mode, and air-preheating mode) and analysed their energy efficiency based on the concentrated parameter model. Owing to the high complexity of the ISGTR system, it is difficult and uneconomical to study and evaluate energy-saving strategies in practical engineering projects. Many changes during the thermal desorption process, water and pollutant content in the soil, or energy consumption, for example, cannot be detected accurately in real time. Hence, it is essential to establish a reliable model to simulate the ISGTR system and the heat and mass transfer of porous media in the soil, thereby defining the employed mode and predicting the effect quantitatively for energy-saving strategies.

Recycle of energy content in off-gas [2] and utilization of waste heat in flue gas [11] are considered two categories of feasible energy-saving methods for ISGTR. Off-gas containing a large number of combustible pollutants is treated through the off-gas treatment system, which increases the operating cost and wastes the combustion heat of pollutants in the offgas. The off-gas burn-back mode is proposed to return the off-gas to the burner, in which the chemical energy of organic vapors in the off-gas is converted into thermal energy by burning. There are two methods for the utilization of waste heat from flue gas. One is to return the heat from the flue gas to the thermal desorption system. In other words, the flue gas that is discharged directly into the atmosphere is returned to the burner mixed with combustion air in a certain proportion. The other is the air-preheating mode, which involves preheating the combustion air by using the residual heat exchange through a preheater.

In this work, the effects of the off-gas burn-back mode, the heat-returning mode, and the air-preheating mode were evaluated. Mathematical and physical models were established by employing conjugate heat transfer to simulate the process of heat and mass transfer in the soil, as well as the combustion process in the burner. The temperature of the soil and flue gas, and the component concentration in soil and off-gas during the thermal desorption process were obtained, which could provide valuable information for the application of energy-saving strategies and operation control. The energy analysis of the ISTGR system was performed based on the combustion models of the burner under three energy-saving strategies, in which the energy utilization ratio and the natural gas consumption were compared.

\section{Concept and Mathematical Models of ISGTR}

2.1. Model of Heat and Mass Transfer. Soil is a typical multicomponent and multiphase porous medium. It consists of many components, including pollutants, water, and soil, and three phases: liquid, gas, and solid. Because of the high specific heat capacity and the latent heat of water, it consumes a lot of energy to heat the soil with a high water content. Therefore, in an actual ISGTR project, precipitation wells are used to pump water out of the soil as much as possible to ensure that the soil reaches an unsaturated state (filled with liquid and gas in the pores), thereby reducing heat consumption.

Heat and mass transfer are the main processes in the soil thermal remediation. In unsaturated soil, mass (pollutants and water) is transferred under the influence of the concentration gradient and the pressure gradient. The main mechanisms of heat transfer are heat conduction and convection. For ISGTR, the conjugate heat transfer can be considered as the heat transport between the fluid (heating gas) and the solid (soil) during the heating process. The solid heat transfer is mainly by conduction, and the fluid heat transfer is mainly by convection. Meanwhile, there is heat conduction and heat convection from soil particles and water, as well as the latent heat that is absorbed by the evaporation of liquid water and pollutants within the soil [12]. In other words, the energy provided by the heating gas is used for soil warming, evaporation, and convection of the liquid phase. The changes in moisture content, pollutant content, temperature in soil, temperature of flue gas, and component concentration in off-gas could be simulated using a continuous distributed parameter model $[13,14]$ in this study.

The following assumptions were made in the model:

(1) The soil was homogeneous and its texture did not change along with the heating well

(2) There was no chemical interaction, and the gas was considered ideal

(3) The distribution of pollutants in the soil was uniform

(4) The pressure in soil was evenly distributed

(5) The solid, liquid, and gas phases were continuous in the unsaturated soil

(6) The migration of liquid and gas, as well as water and pollutant, did not affect each other

2.1.1. Governing Equations of Mass Transfer in Unsaturated Soil. The variable amount of liquid water in the soil is equal to the difference between the amount of migration and the amount of inside evaporation. The volume fraction of the liquid in the soil $\theta_{\mathrm{w}}$ is solved according to the following equation:

$$
\rho_{\mathrm{w}} \frac{\partial \theta_{\mathrm{w}}}{\partial t}=\nabla \cdot\left(\rho_{\mathrm{w}} D_{\mathrm{w}} \nabla \theta_{\mathrm{w}}\right)-\dot{m}_{\mathrm{wg}}
$$

where $D_{\mathrm{w}}\left(\mathrm{m}^{2} / \mathrm{s}\right)$ is the diffusion coefficient of the liquid, $m_{\mathrm{wg}}$ $\left(\mathrm{kg} /\left(\mathrm{m}^{3} \cdot \mathrm{s}\right)\right)$ is the evaporation rate of water, and $\rho_{\mathrm{w}}\left(\mathrm{kg} / \mathrm{m}^{3}\right)$ is the density of liquid water.

The evaporation rate of liquid water is related to the difference in pressure between the saturated vapor pressure of water vapor in the soil and the vapor pressure of the upper air. Evaporation ceases once the amount of liquid phase reaches zero (fully evaporated) or if the local vapor pressure does not exceed the headspace vapor pressure (no driving force for evaporation). 


$$
\begin{aligned}
& \dot{m}_{\mathrm{wg}}=\frac{k_{\mathrm{evap}} \rho_{\mathrm{w}}\left(p^{*}-p_{\mathrm{g}}\right)}{p_{\mathrm{g}}} \quad\left(\text { if } \theta_{\mathrm{w}}>0\right), \\
& \dot{m}_{\mathrm{wg}}=0 \quad\left(\text { if } \theta_{\mathrm{w}} \leq 0 \text { or } p^{*} \leq p_{\mathrm{g}}\right),
\end{aligned}
$$

where $k_{\text {evap }}(1 / \mathrm{s})$ is the evaporation rate constant, $p^{*}(\mathrm{~Pa})$ is the saturated vapor pressure, and $p_{\mathrm{g}}(\mathrm{Pa})$ is the top air vapor pressure.

The saturated vapor pressure of water vapor, which is related to temperature, can be calculated using the Antoine equation [15]:

$$
\log _{10} p^{*}=A-\frac{B}{C+T}
$$

where $A, B$, and $C$ are Antoine constants.

Water migrates in the soil due to capillary flow. Water transport through the soil can be approximated as a diffusion process. Therefore, when there is a gradient in the volume fraction of water, the water migrates from the high volume fraction region to the low region. The water diffusion coefficient $D_{\mathrm{w}}$ is calculated using the hydraulic conductivity $K_{\mathrm{w}}$ and soil water potential $\psi[16,17]$.

$$
D_{\mathrm{w}}=K_{\mathrm{w}} \frac{\partial \psi}{\partial \theta_{\mathrm{w}}} .
$$

The migration process of pollutants is the same as that of water, and the diffusion coefficient, evaporation rate constant, residual saturation, and proportion constant are different. On the basis of the results of mass transfer in soil, the concentration variation of water and pollutants in off-gas could be obtained because of mass conservation.

2.1.2. Governing Equations of Heat Transfer. The heat transfer process in the soil is mainly affected by thermal conductivity, heat capacity, and density of the soil. During the thermal desorption process, as a result of the extraction of water and pollutants, the contents of water, pollutants, and gas in the soil are constantly changing. The evaporation of water and pollutants causes a continuous change in the thermal conductivity, heat capacity, and density of the soil. The sum of three-phase volume fractions should be equal to one. Therefore, the volume fraction of gas in the soil $\theta_{\mathrm{v}}$ can be calculated using the constant particle volume fraction of soil $\theta_{\mathrm{s}}$, the variable volume fraction of water $\theta_{\mathrm{w}}$, and the variable volume fraction of pollutant $\theta_{\mathrm{p}}$ :

$$
\theta_{\mathrm{v}}=1-\theta_{\mathrm{w}}-\theta_{\mathrm{s}}-\theta_{\mathrm{p}}
$$

The effective density $\rho_{\text {eff }}$, effective specific heat capacity $c_{\mathrm{p} \text {,eff }}$, and effective thermal conductivity coefficient $\lambda_{\text {eff }}$ of soil can be calculated using the volume average method [18]:

$$
\begin{gathered}
\rho_{\text {eff }}=\theta_{\mathrm{w}} \rho_{\mathrm{w}}+\theta_{\mathrm{s}} \rho_{\mathrm{s}}+\theta_{\mathrm{v}} \rho_{\mathrm{v}}+\theta_{\mathrm{p}} \rho_{\mathrm{p}}, \\
c_{\mathrm{p}, \mathrm{eff}}=\frac{\theta_{\mathrm{w}} \rho_{\mathrm{w}} c_{\mathrm{p}, \mathrm{w}}+\theta_{\mathrm{s}} \rho_{\mathrm{s}} c_{\mathrm{p}, \mathrm{s}}+\theta_{\mathrm{v}} \rho_{\mathrm{v}} c_{\mathrm{p}, \mathrm{v}}+\theta_{\mathrm{p}} \rho_{\mathrm{p}} c_{\mathrm{p}, \mathrm{p}}}{\rho_{\mathrm{eff}}}, \\
\lambda_{\text {eff }}=\lambda_{\mathrm{dry}}+\frac{\theta_{\mathrm{w}}+\theta_{\mathrm{p}}}{1-\theta_{\mathrm{s}}}\left(\lambda_{\mathrm{wet}}-\lambda_{\mathrm{dry}}\right),
\end{gathered}
$$

where $\rho_{\mathrm{s}}, \rho_{\mathrm{v}}$, and $\rho_{\mathrm{p}}\left(\mathrm{kg} / \mathrm{m}^{3}\right)$ are the densities of the soil, soil gas, and pollutant, respectively. $c_{\mathrm{p}, \mathrm{s}}, c_{\mathrm{p}, \mathrm{w}}, c_{\mathrm{p}, \mathrm{v}}$, and $c_{\mathrm{p}, \mathrm{p}}(\mathrm{J} /$ $(\mathrm{kg} \cdot \mathrm{K}))$ are the specific heat capacities of the soil, water, soil gas, and pollutant, respectively. $\lambda_{\text {dry }}(\mathrm{W} /(\mathrm{m} \cdot \mathrm{K}))$ and $\lambda_{\text {wet }}(\mathrm{W} /$ $(\mathrm{m} \cdot \mathrm{K}))$ are the thermal conductivity coefficients of dry and wet soil, respectively.

The governing equation for conjugate heat transfer in ISGTR is as follows. According to the energy conservation equation, the soil temperature $T_{s}\left({ }^{\circ} \mathrm{C}\right)$ and flue gas temperature $T_{\mathrm{g}}\left({ }^{\circ} \mathrm{C}\right)$ can be obtained by the governing equations. The heat transfer in the soil satisfies Equation (7), and governing Equation (8) is used for the heat transfer of the heating gas:

$$
\begin{aligned}
& \rho_{\text {eff }} c_{\mathrm{p}, \mathrm{eff}} \frac{\partial T_{\mathrm{s}}}{\partial t}=\nabla\left(\lambda_{\mathrm{eff}} \nabla T_{\mathrm{s}}\right)+\left(\rho_{\mathrm{w}} D_{\mathrm{w}} \nabla \theta_{\mathrm{w}}\right) c_{\mathrm{p}, \mathrm{w}} T_{\mathrm{s}} \\
& +\left(-\dot{m}_{\mathrm{wg}} \Delta H_{\mathrm{vap}}\right)+\left(-\dot{m}_{\mathrm{pg}} \Delta H_{\mathrm{vapp}}\right) \\
& \rho_{\mathrm{g}} C_{\mathrm{g}} \frac{\partial T_{\mathrm{g}}}{\partial t}+\rho_{\mathrm{g}} C_{\mathrm{g}} u \nabla T_{\mathrm{g}}=\nabla\left(\lambda_{\mathrm{g}} \nabla T_{\mathrm{g}}\right),
\end{aligned}
$$

where $\Delta H_{\text {vapp }}(\mathrm{J} / \mathrm{kg})$ is the latent heat of evaporation of the liquid pollutant, $m_{\mathrm{pg}}\left(\mathrm{m}^{2} / \mathrm{s}\right)$ is the evaporation rate of liquid pollutant, $\lambda_{\mathrm{g}}(\mathrm{W} /(\mathrm{m} \cdot \mathrm{K}))$ is the thermal conductivity coefficient of the heating gas fluid, $\rho_{\mathrm{g}}\left(\mathrm{kg} / \mathrm{m}^{3}\right)$ is the density of the heating gas fluid, $C_{\mathrm{g}}(\mathrm{J} /(\mathrm{kg} \cdot \mathrm{K}))$ is the heat capacity of the heating gas fluid, and $u(\mathrm{~m} / \mathrm{s})$ is the velocity of the heating gas fluid.

2.2. Model of Combustion Process in Burner. The heating gas is produced by the combustion of natural gas and combustion air in the burner. Figure 1 shows the gas flow in ISGTR traditionally, which was named the basic method (BM) in this paper. Excess air is usually introduced to ensure complete combustion of natural gas [19]. The ratio of excess air to the theoretical amount of air for natural gas combustion is defined as the excess air coefficient $\alpha$.

If natural gas is considered $100 \%$ methane $\left(\mathrm{CH}_{4}\right)$, combustion air is considered to consist of $78.79 \%$ nitrogen and $21.21 \%$ oxygen. The combustion equation is obtained as follows:

$$
\mathrm{CH}_{4}+2(1+\alpha) \mathrm{O}_{2}+7.429(1+\alpha) \mathrm{N}_{2} \longrightarrow \mathrm{CO}_{2}+2 \mathrm{H}_{2} \mathrm{O}++7.429(1+\alpha) \mathrm{N}_{2}+2 \alpha \mathrm{O}_{2}+Q
$$




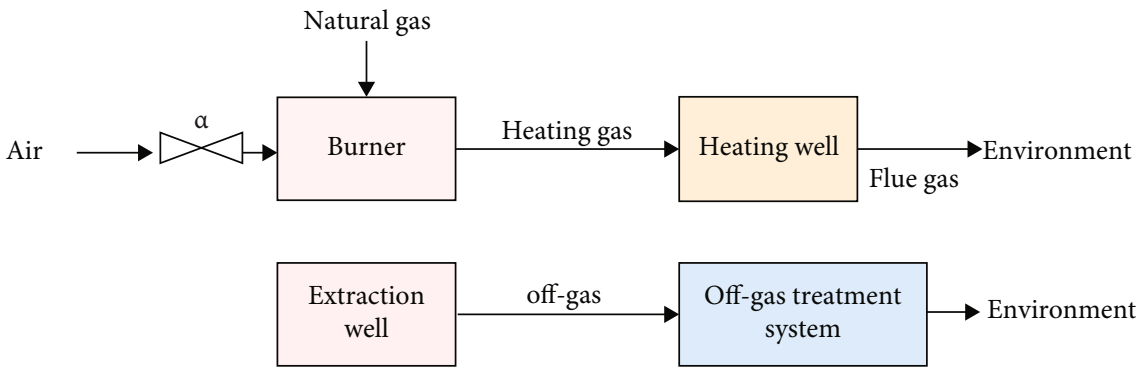

FIgURe 1: Flow diagram of gas in BM system.

where $Q$ indicates the heat generated by combustion.

The heating gas produced by methane combustion is a mixture of different gases. Assuming that all gases were ideal gases in the study, the average specific heat of the heating gas $\left(C_{\mathrm{g}}\right)$ could be calculated as follows:

$$
C_{\mathrm{g}}=C_{\mathrm{CO}_{2}} \cdot \mathscr{W}_{\mathrm{CO}_{2}}+C_{\mathrm{H}_{2} \mathrm{O}} \cdot \mathscr{W}_{\mathrm{H}_{2} \mathrm{O}}+C_{\mathrm{N}_{2}} \cdot \mathscr{W}_{\mathrm{N}_{2}}+C_{\mathrm{O}_{2}} \bullet \mathscr{W}_{\mathrm{O}_{2}},
$$

where the proportions of each gas $\mathscr{W}_{\mathrm{CO}_{2}}, \mathscr{W}_{\mathrm{H}_{2} \mathrm{O}}, \mathscr{W}_{\mathrm{N}_{2}}, \mathscr{W}_{\mathrm{O}_{2}}$ can be obtained according to the combustion equation. The molar specific heat of the components in the heating gas can be obtained from the literature [19]. Thus, Equation (10) is transformed into Equation (11):

$$
C_{\mathrm{g}}=A+B \cdot\left(t^{\prime}+t_{0}\right)
$$

where $t_{0}$ and $t^{\prime}$ are the gas centigrade temperature before combustion and the centigrade temperature of the heating gas, respectively. $A$ and $B$ are $(403.338+273.068 \alpha) /(10.429$ $+9.429 \alpha)$ and $(0.0254434 \alpha+0.0404134) /(10.429+9.429 \alpha)$.

According to the law of energy conservation, the combustion heat of methane is used to heat the combustion products and vaporize the water. Furthermore, the combustion efficiency $\xi$ was introduced (usually set as 0.8 ), and $t_{0}$ was assumed to be 0 here because $t_{0}$ is usually extremely low [20]. Thus, the mathematical model of the burner is as follows:

$$
G_{\mathrm{NmolBM}} \xi q_{\mathrm{N}}=G_{\text {gmol }}\left(A t^{\prime}+B t^{\prime 2}+\mathscr{W}_{\mathrm{H}_{2} \mathrm{O}} \cdot \gamma_{\mathrm{H}_{2} \mathrm{O}}\right),
$$

where $G_{\text {NmolBM }}$ is the molar flow of natural gas in the BM system, $G_{\text {gmol }}$ is the molar flow of heating gas, $\mathscr{W}_{\mathrm{H}_{2} \mathrm{O}}$ is the water content of the heating gas, $\gamma_{\mathrm{H}_{2} \mathrm{O}}$ is the latent heat of water, and $q_{\mathrm{N}}$ is the low calorific value of methane combustion [21]. And according to Equation (9), the relationship between natural gas and heating gas is as follows:

$$
G_{\mathrm{NmolBM}}=\frac{1}{10.429+9.429 \alpha} G_{\mathrm{gmol}} .
$$

Equation (13), $A$, and $B$ are substituted into Equation (12); the relationship between the excess air coefficient and the temperature of the heating gas is as follows:

$$
\alpha=\frac{\xi q_{\mathrm{N}}-2 \cdot \gamma_{\mathrm{H}_{2} \mathrm{O}}-403.338 t^{\prime}-0.0404134 t^{\prime 2}}{273.068 t^{\prime}+0.0254434 t^{\prime 2}} .
$$

2.3. Physical Model of Heating Unit. Contaminated soil remediation projects generally take up a large area with many heating wells. Based on a specific remediation project, a typical cylindrical soil unit with a heating well was taken as the research object. The two-dimensional axisymmetric geometric model of the heating unit established via COMSOL Multiphysics ${ }^{\circledR}$ 5.4 software is shown in Figure 2. COMSOL software is commonly used for multiphysical field coupling simulation, which could simulate the real physical phenomena based on finite element analysis. The physical model contained soil, a heating well, and an insulation layer. The depth and radius of the soil unit were $1.6 \mathrm{~m}$ and $1.1 \mathrm{~m}$. An insulation layer of $0.4 \mathrm{~m}$ thickness was set to inhibit the emission of pollutants from the surface and the dissipation of heat on the surface. In this model, the soil was assumed to contain toluene with a volume fraction of $6 \%$. A vacuum effect $(3000 \mathrm{~Pa})$ was required to extract water vapor and pollutant vapor from the soil. The heating gas temperature was set at $800^{\circ} \mathrm{C}$, and the molar flow was stable and equal to the off-gas flow. The values of the input parameters for the physical model are listed in Table S1 in the Supplementary Materials, thus performing a numerical analysis based on the governing equations of heat and mass transfer. The most unfavorable point under heating at the outermost bottom of the soil in the physical model is selected to simulate the variation of substances and temperature in the soil at the boundary.

\section{Models and Evaluation Methods for Energy- Saving Strategies}

The gas flow under the three energy-saving strategies, as shown in Figure 3, was different from that of the BM system. To compare the effects of the different strategies, many cases were designed as follows:

(i) Case $\mathrm{OB}$ was applied for the off-gas burn-back mode. The off-gas recycling ratio $(c)$ was adjusted according to the pollutant and water volume fraction of the off-gas. The molar flow of air $(n)$, which took place in the excess air coefficient $\alpha$ here, was introduced to stabilize the flue gas flow and temperature 


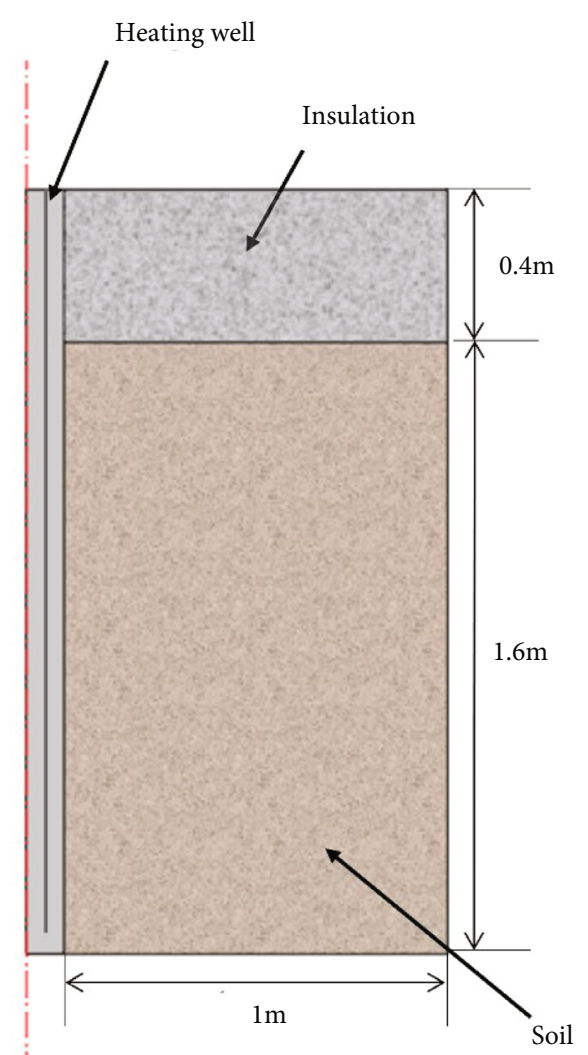

Figure 2: Two-dimensional axisymmetric geometric model of heating unit for simulation.

(ii) Three cases, Cases 3.1, 3.2, and 3.3, were designed for the energy-saving strategy of the heat-returning mode; the reflux ratios of the flue gas $\beta$ were 0.1 , 0.3 , and 0.5 , respectively

(iii) There are two cases, Cases 4.1 and 4.2 , which were designed for the air-preheating mode. The preheating ratios of combustion air were 0.5 and 1.0, respectively

The reflux ratio and preheating ratio were selected in consideration of full energy utilization and ensuring the complete combustion of natural gas. In different energysaving strategies, the flow of combustion air and natural gas was adjusted in real time according to the temperature of the flue gas and pollutant and the water volume fraction of the off-gas to maintain the temperature $\left(800^{\circ} \mathrm{C}\right)$ and the flow of the heating gas. Because of the slight variation in the value of the average specific heat of the heating gas in the combustion process, it was assumed that $C_{\mathrm{g}}$ was stable and constant in three energy-saving modes.

3.1. Model of Off-Gas Burn-Back Mode. In the off-gas burnback mode, there is also exothermic combustion of the pollutant (toluene) in addition to the combustion of natural gas in the burner. The equation for toluene combustion is as follows.

$$
\mathrm{C}_{7} \mathrm{H}_{8}+9 \mathrm{O}_{2}+33.429 \mathrm{~N}_{2} \longrightarrow 7 \mathrm{CO}_{2}+4 \mathrm{H}_{2} \mathrm{O}+33.429 \mathrm{~N}_{2} \text {. }
$$

To maintain the temperature and flow of the heating gas, natural gas and air need to be introduced at the right time, and the recycling ratio of off-gas needs to be adjusted in real time according to the toluene concentration in the off-gas. When the volume fraction of toluene in the off-gas is relatively small, there is much excess air in the off-gas. The gas temperature of toluene combustion could not reach the set temperature of the heating gas; therefore, it is necessary to introduce natural gas. Thus, the energy conservation equation for the off-gas burn-back mode is as follows:

$$
G_{\mathrm{NmolOB}} \xi q_{\mathrm{N}}+G_{\mathrm{BNmol}} \xi q_{\mathrm{BN}}=G_{\mathrm{gmol}}\left(C_{\mathrm{g}} t^{\prime}+\mathscr{W}_{\mathrm{H}_{2} \mathrm{O} \_\mathrm{OB}} \cdot \gamma_{\mathrm{H}_{2} \mathrm{O}}\right)
$$

where $G_{\mathrm{NmolOB}}$ is the molar flow of natural gas in this mode, $G_{\mathrm{BNmol}}$ is the molar flow of toluene, $q_{\mathrm{BN}}$ is the low calorific value of combustion of toluene, and $\mathscr{W}_{\mathrm{H}_{2} \mathrm{O}-\mathrm{OB}}$ is the moisture content in the off-gas.

In this study, the molar flow of the off-gas was assumed to be equal to the heating gas flow. Hence, as the recycle ratio of the off-gas is $c$, the molar flow of toluene is calculated using Equation (17):

$$
G_{\mathrm{BNmol}}=G_{\mathrm{gmol}} c \theta_{\mathrm{g}, \mathrm{p}},
$$

where $\theta_{\mathrm{g}, \mathrm{p}}$ is the volume fraction of toluene in the off-gas, which can be calculated from the change in the volume fraction of toluene in the soil.

$\mathscr{W}_{\mathrm{H}_{2} \mathrm{O}-\mathrm{OB}}$ can be obtained from the combustion equation of toluene and natural gas:

$$
\mathscr{W}_{\mathrm{H}_{2} \mathrm{O} \_\mathrm{OB}}=\frac{2 G_{\mathrm{NmolOB}}}{G_{\text {gmol }}}+4 c \theta_{\mathrm{g}, \mathrm{p}}
$$

In this situation, according to the equation of combustion of natural gas and toluene, the molar flow of natural gas is as follows:

$$
G_{\mathrm{NmolOB}}=\frac{1-c\left(1+\theta_{\mathrm{g}, \mathrm{p}}\right)}{10.429} G_{\mathrm{gmol}} .
$$

When the volume fraction of toluene in the off-gas reaches a certain level, the gas temperature from toluene combustion is higher than the target temperature. Extra air needs to be introduced to maintain the temperature of the heating gas, while the natural gas could be absent. The energy conservation under the circumstance is as follows:

$$
G_{\mathrm{BNmol}} \xi q_{\mathrm{BN}}=G_{\text {gmol }}\left(C_{\mathrm{g}} t^{\prime}+\mathscr{W}_{\mathrm{H}_{2} \mathrm{O} \_\mathrm{OB}} \cdot \gamma_{\mathrm{H}_{2} \mathrm{O}}\right) .
$$

And $\mathscr{W}_{\mathrm{H}_{2} \mathrm{O}-\mathrm{OB}}$ is only from the combustion of toluene.

$$
\mathscr{W}_{\mathrm{H}_{2} \mathrm{O} \_\mathrm{OB}}=4 c \theta_{\mathrm{g}, \mathrm{p}} .
$$

Due to the stable flow of the heating gas, the molar flow of the introduced air is as follows: 


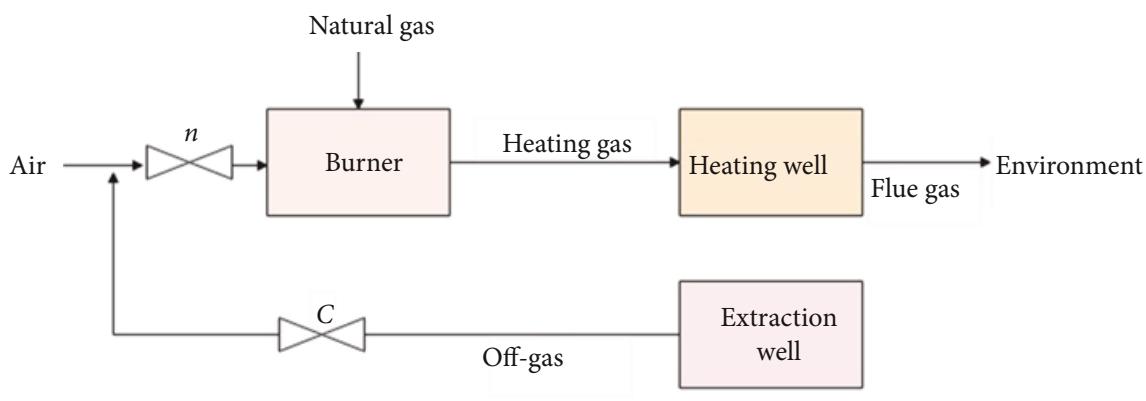

(a)

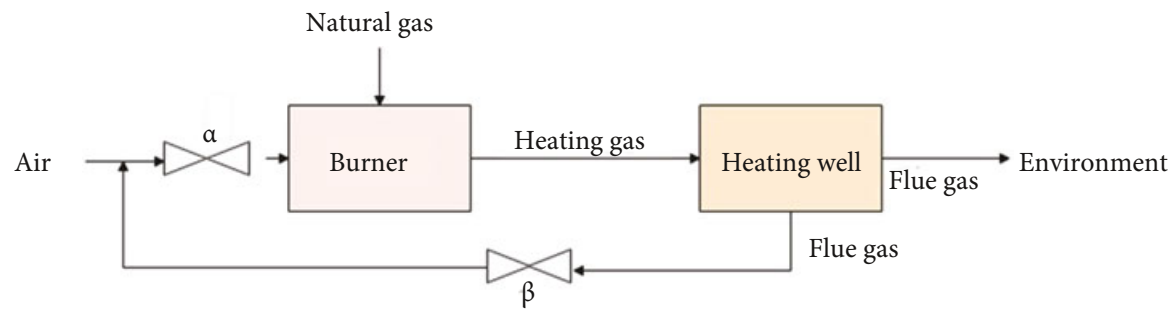

(b)

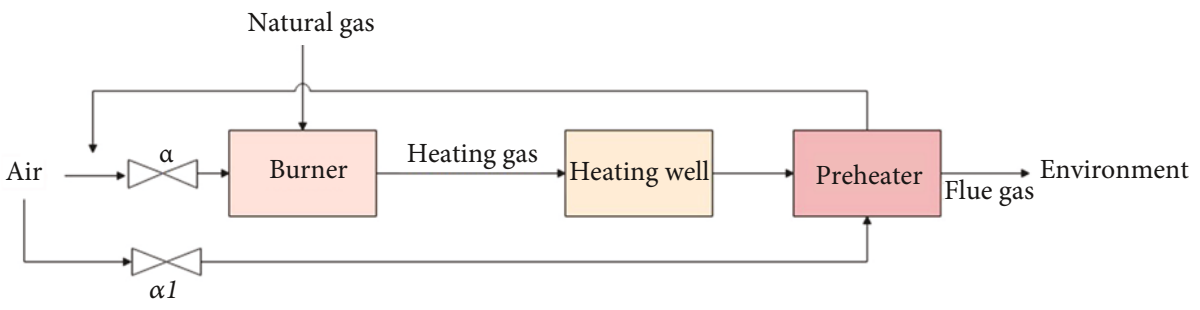

(c)

FIGURE 3: Flow diagrams of gas in ISGTR system in three energy-saving strategies: (a) off-gas burn-back mode; (b) heat-returning mode; (c) air-preheating mode.

$$
n=G_{\text {gmol }}\left(1-c-c \theta_{\mathrm{g}, \mathrm{p}}\right)
$$

According to the above equations, it can be calculated that when the volume fraction of toluene in the off-gas reaches $1.01 \%$, the recycle ratio of the off-gas reaches the maximum (0.99), which can maintain a stable heating gas. With the continued increase in the volume fraction of toluene in the off-gas, it is supposed to reduce the recycle ratio of off-gas and add more air.

3.2. Model of Heat-Returning Mode. When the energy-saving strategy of the heat-returning mode is adopted, there is no new energy, and the combustion equation remains unchanged. The energy conservation equation is as follows:

$G_{\mathrm{NmolHR}} \xi q_{\mathrm{N}}+\beta G_{\mathrm{gmol}} C_{\mathrm{g}} T_{\mathrm{g}}=G_{\mathrm{gmol}}\left(C_{\mathrm{g}} t^{\prime}+\mathscr{W}_{\mathrm{H}_{2} \mathrm{O} \_\mathrm{HR}} \cdot \gamma_{\mathrm{H}_{2} \mathrm{O}}\right)$,

where $G_{\mathrm{NmolHR}}$ is the molar flow of natural gas in this mode, $\beta$ and $T_{\mathrm{g}}$ are the reflux ratio and temperature of the flue gas, respectively, and $\mathscr{W}_{\mathrm{H}_{2} \mathrm{O} \_\mathrm{HR}}$ is the moisture content from natural gas combustion.

$$
\mathscr{W}_{\mathrm{H}_{2} \mathrm{O} \_\mathrm{HR}}=\frac{2(1-\beta)}{10.429+9.429 \alpha} .
$$

Meanwhile, the ratio of natural gas to flue gas conforms to the combustion equation.

$$
G_{\mathrm{NmolHR}}=\frac{1-\beta}{10.429+9.429 \alpha} G_{\mathrm{gmol}} \cdot
$$

Thus, the consumption of natural gas could be calculated through the above equations.

3.3. Model of Air-Preheating Mode. This is similar to the heat-returning mode, where there is no change in the combustion reaction under the energy-saving strategy of air preheating. However, energy consumption changes when the air-preheating mode is adopted compared to the basic method. It was assumed that the heat exchange efficiency of the preheater was $100 \%$, and the parallel-flow heat exchange reached its limit. After preheating, the temperature of the preheated air $t_{\mathrm{pa}}$ satisfies the energy conversation equation below:

$$
G_{\mathrm{air}} C_{\mathrm{air}} \cdot\left(t_{\mathrm{pa}}-t_{0}\right)=G_{\mathrm{gmol}} C_{\mathrm{g}} \cdot\left(T_{\mathrm{g}}-t_{\mathrm{pa}}\right),
$$


where $G_{\text {air }}$ is the molar flow of preheated air and $C_{\text {air }}$ is the molar specific heat of preheated air $(29.145 \mathrm{~J} /(\mathrm{mol} \mathrm{K}))$.

The energy conservation for the burner could be expressed by the following equation.

$$
G_{\mathrm{NmolAP}} \xi q_{\mathrm{N}}+G_{\text {air }} C_{\text {air }} t_{\mathrm{pa}}=G_{\text {gmol }}\left(C_{\mathrm{g}} t^{\prime}+\mathscr{W}_{\mathrm{H}_{2} \mathrm{O} \_\mathrm{AP}} \cdot \gamma_{\mathrm{H}_{2} \mathrm{O}}\right)
$$

where $G_{\mathrm{NmolAP}}$ is the molar flow of natural gas and $\mathscr{W}_{\mathrm{H}_{2} \mathrm{O} \_\mathrm{AP}}$ is the moisture content of the off-gas in this mode.

Additionally, $\mathscr{W}_{\mathrm{H}_{2} \mathrm{O} \_ \text {AP }}$ and $G_{\mathrm{NmolAP}}$ could be calculated according to the combustion reaction equation.

$$
\begin{gathered}
\mathscr{W}_{\mathrm{H}_{2} \mathrm{O} \_\mathrm{AP}}=\frac{2}{10.429+9.429 \alpha}, \\
G_{\mathrm{NmolAP}}=\frac{1}{10.429+9.429 \alpha} G_{\mathrm{gmol}} .
\end{gathered}
$$

3.4. Evaluation Methods. Based on each burner model established here, we determined the ratio of natural gas consumption (relative natural gas consumption) between the energysaving strategy and the basic method. A comparison of natural gas consumption directly reflects the energy-saving effect.

In addition, the energy utilization ratio is an important performance indicator for energy analysis, and it is calculated by the energy that is ultimately used and the energy that is input into the soil. The total input energy is equivalent to the low calorific value of the natural gas consumed. The energy utilization of the basic method can be obtained using the following equation:

$$
\eta_{\mathrm{BM}}=\frac{q_{\mathrm{s}}}{G_{\mathrm{NmolBM}} q_{\mathrm{N}} T},
$$

where $q_{\mathrm{s}}$ is the energy that soil ultimately uses and $T$ is the specified heating duration, which is determined by the simulation result of the temperature change periods in the soil in this study.

The energy used by the soil is equal to the energy released from the temperature variation of the flue gas. Defining $t_{i}^{\prime \prime}$ is the temperature of the flue gas after heating $i$ hours, which is simulated by the governing equation of heating transfer via COMSOL software. Thus, $q_{\mathrm{s}}$ can be calculated using the following equation.

$$
q_{\mathrm{s}}=G_{\mathrm{gmol}} C_{\mathrm{g}} \sum_{i=1}^{T}\left(t_{i}^{\prime \prime}-t^{\prime}\right) \text {. }
$$

Combining with Equation (12) in Section 2.2, when the temperature of the heating gas remains constant, Equation (29) can be rewritten as follows:

$$
\eta_{\mathrm{BM}}=\frac{\xi G_{\mathrm{gmol}} C_{\mathrm{g}} \sum_{i=1}^{T}\left(t_{i}^{\prime \prime}-t^{\prime}\right)}{T G_{\mathrm{gmol}}\left(C_{\mathrm{g}} t^{\prime}+\mathscr{W}_{\mathrm{H}_{2} \mathrm{O}} \cdot \gamma_{\mathrm{H}_{2} \mathrm{O}}\right)} .
$$

Furthermore, the energy utilization ratios of different energy-saving strategies can be obtained.

$$
\begin{aligned}
& \eta_{\mathrm{OB}}=\eta_{\mathrm{BM}} \cdot \frac{\int_{0}^{T} G_{\mathrm{NmolBM}} d t}{\int_{0}^{T} G_{\mathrm{NmolOB}} d t}, \\
& \eta_{\mathrm{HR}}=\eta_{\mathrm{BM}} \cdot \frac{\int_{0}^{T} G_{\mathrm{NmolBM}} d t}{\int_{0}^{T} G_{\mathrm{NmolHR}} d t}, \\
& \eta_{\mathrm{AP}}=\eta_{\mathrm{BM}} \cdot \frac{\int_{0}^{T} G_{\mathrm{NmolBM}} d t}{\int_{0}^{T} G_{\mathrm{NmolAP}} d t} .
\end{aligned}
$$

\section{Results and Discussion}

4.1. Simulation Results of Heat and Mass Transfer in ISGTR Model. The simulation results of the temperature variation in the boundary soil and the flue gas during the assumed heating time of $850 \mathrm{~h}$ are shown in Figure 4 . The trend of change in temperature in soil was consistent with that reported by Smallwood [15]. Nevertheless, in his study, similar results were simulated by adopting a model of electrical thermal remediation, which was different from the conjugate heat transfer model of ISGTR. The temperature rise curve of the boundary soil could be divided into three stages, with different stages lasting for different periods. In Stage I, $340 \mathrm{~h}$ was required for the temperature of the boundary soil to rise from the initial temperature $\left(20^{\circ} \mathrm{C}\right)$ to the boiling point of water at a given partial pressure. Then, it remained almost constant at the boiling point of water in Stage II for $195 \mathrm{~h}$ until the water was completely evaporated (initial water content in the soil of 25\%). Hence, the energy consumption in Stages I and II is related to the moisture content in the soil, which is the reason why the groundwater is suggested to be pumped out before remediation in an actual project. The last $315 \mathrm{~h}$ was Stage III, in which the temperature finally increased to $325^{\circ} \mathrm{C}$. From the simulation results, it took only approximately $5 \mathrm{~h}$ for the soil temperature reaching the boiling point of toluene (target temperature) from the end of Stage II. In an actual project, when the temperature of the cooling point (the lowest temperature point in the remediation area) reaches the target temperature, the ISGTR system enters the heat preservation stage. However, in Figure 4, there was no plateau at the boiling point of toluene due to the lower latent heat and lower concentration of toluene compared to water in the soil. It can also be seen that the soil heating rate in Stage III was higher than that in Stage I. This is because all the water in the soil evaporates in Stage II, resulting in a decrease in the specific heat capacity of the soil, and less energy is required to raise the soil temperature to the same level.

The variation in the temperature of the flue gas was different from that of the soil. It increased from $119^{\circ} \mathrm{C}$ to $374^{\circ} \mathrm{C}$ in Stage I, $402^{\circ} \mathrm{C}$ in Stage II, and $515^{\circ} \mathrm{C}$ in Stage III. The temperature difference between the heating gas $\left(800^{\circ} \mathrm{C}\right)$ and soil $\left(20^{\circ} \mathrm{C}\right)$ was the largest at first, which ensured maximum heat exchange. With an increase in soil temperature, the temperature difference became smaller, which led to a decrease in the efficiency of heating gas utilization and a gradual 


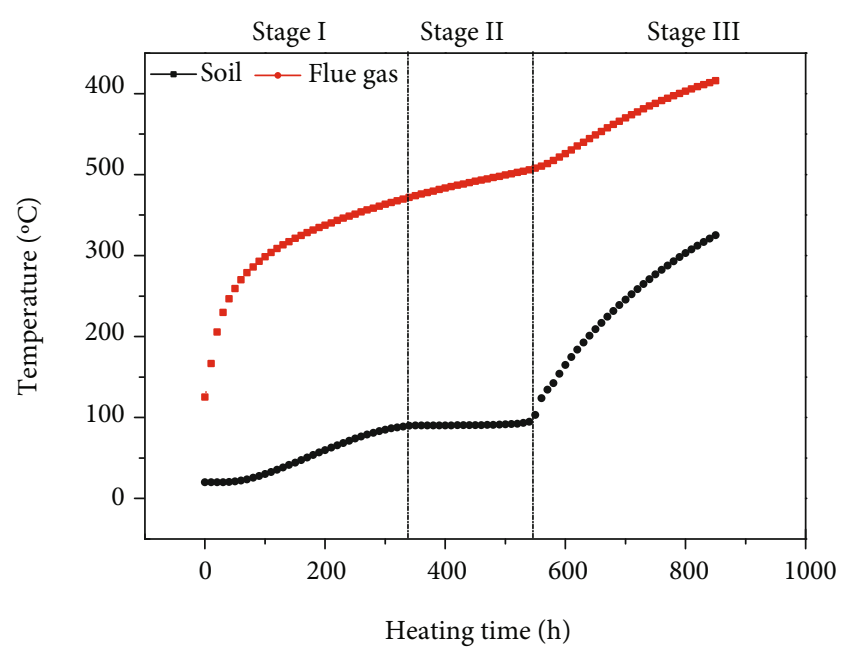

Figure 4: Variation of the temperature of the soil at the boundary and flue gas with heating time.

increase in the temperature of the flue gas. According to the trend of flue gas temperature illustrated in Figure 4, it was also proved that a large portion of heat was not used by the soil and was exhausted directly. Thus, recycling flue gas is feasible and necessary, which lowers the energy consumption of the ISGTR.

The volume fraction change of toluene and water at the boundary soil was simulated using the mass transfer model, and the results are shown in Figure 5(a). The volume fraction of water continuously decreased to 0 from the start of heating until the end of Stage II. The water transfer relies on the concentration gradient mainly in Stage I and then continues to vaporize in Stage II. However, there was no obvious decline in the volume fraction of toluene in Stages I and II. When the temperature reached its boiling point, the volume fraction of toluene declined rapidly, which lasted for approximately $45 \mathrm{~h}$ (from $540 \mathrm{~h}$ to $585 \mathrm{~h}$ ). The vaporization periods of water and toluene were different ( $195 \mathrm{~h}$ vs. $45 \mathrm{~h}$ ) due to their different latent heat of vaporization $(2256 \mathrm{~kJ} / \mathrm{kg}$ vs. $360.70 \mathrm{~kJ} /$ $\mathrm{kg}$ ) and their contents in the soil. From the simulation results, the moment for the end of the remediation could be obtained, that is $585 \mathrm{~h}$, when the volume fraction of toluene at the boundary soil dropped to 0 . The volume fraction of toluene and water in the off-gas could also be calculated based on their volume fraction in the soil, as shown in Figure 5(b). The volume fraction of water in the off-gas increased gradually at the beginning and then became rapidly from $340 \mathrm{~h}$ and to the peak at $530 \mathrm{~h}$. In contrast, the volume fraction of toluene in the off-gas was almost zero before $540 \mathrm{~h}$ and then rose rapidly. This indicates that the off-gas could be recycled only during Stage III. Taking into account the end of the remediation, the subsequent energy analysis of energy-saving strategies in Stage III was carried out only for the time corresponding to the toluene vaporization period ( $45 \mathrm{~h})$.

4.2. Energy Analysis of Off-Gas Burn-Back Mode. The energy-saving measure of off-gas burn-back is to return the extracted off-gas into the burner to utilize the combustion heat of pollutants in the off-gas. It is worth noting that the volume fraction of organic vapors and water vapor in the offgas should be monitored in real time to select the optimal timing for off-gas recycling. Too much water vapor in the off-gas increases heat loss and the risk of pipe clogging, while too little organic vapor makes combustion difficult. Thus, when the concentration of organic vapor reaches the combustion condition and the concentration of water vapor is relatively low, the offgas can be delivered to the burner. From Figure 5, after the water volume fraction dropped to 0 , the period from the toluene volume fraction started to increase significantly (approximately at $540 \mathrm{~h}$ ) to that decreased to 0 (approximately at $585 \mathrm{~h}$ ) was considered suitable for off-gas recycling.

In the off-gas burn-back mode, the flow of natural gas varies with the toluene volume fraction in the off-gas. Figure 6(a) shows the relative natural gas consumption change during the process. The calorific value of toluene is higher than methane $(3905.0 \mathrm{~kJ} /(\mathrm{mol} \cdot \mathrm{K})$ vs. $802.65 \mathrm{~kJ} /(\mathrm{mol} \cdot \mathrm{K}))$, so the natural gas flow rate dropped by approximately $31.2 \%$ as soon as the off-gas returned back to the burner. From $540 \mathrm{~h}$ to $553 \mathrm{~h}$, the toluene concentration in the off-gas increased rapidly, and the natural gas consumption fell rapidly correspondingly. Then, the volume fraction of toluene in the off-gas continued to rise until $585 \mathrm{~h}$, and the required natural gas flow was reduced to 0 . At $585 \mathrm{~h}$, when all the toluene in the soil was extracted, the natural gas flow returned to its original level. After heating for $585 \mathrm{~h}, 3.37 \%$ of the energy could be saved using the energy-saving strategy of off-gas burn-back.

The results of the energy utilization ratio in the off-gas burn-back mode and the basic method are shown in Figure 6(b). The energy utilization ratios of the three stages in Case BM were $45.31 \%, 38.14 \%$, and $36.09 \%$, respectively. This decline in the energy utilization ratio is mostly due to the falling temperature difference between the soil and the heating gas. In Case OB, the off-gas was only recycled in Stage III, and the energy utilization ratio of Stage III was promoted to $87.80 \%$ and $51.71 \%$ higher than in Case BM. In actual engineering projects, the pollutants in soil are not single but mixtures of complex components in most cases with a wide distillation range. This would increase the length of time for off-gas burn-back and the recoverable combustion heat of organic pollutants. Off-gas burn-back mode can save energy in practical applications more significantly. Moreover, the heating temperature would be too high if all off-gas returns to the burner; thus, it is necessary to adjust the reflux ratio of the off-gas to maintain the heating gas temperature at the target temperature.

4.3. Energy Analysis of Heat-Returning Mode. For the energy-saving strategy of the heat-returning mode, the reflux ratios of flue gas in Cases 3.1, 3.2, and 3.3 were $0.1,0.3$, and 0.5 , respectively. The change in the required natural gas flow was calculated based on the change in the flue gas recycle ratio and flue gas temperature obtained via the model of the heating field.

Figure 7 (a) shows that the energy utilization ratios of the three cases were all higher than that of Case BM, and the energy utilization ratio increased with an increase in the flue gas reflux ratio. Regardless of the stage, Case 3.3 had the highest energy utilization ratio, which implies the most significant 


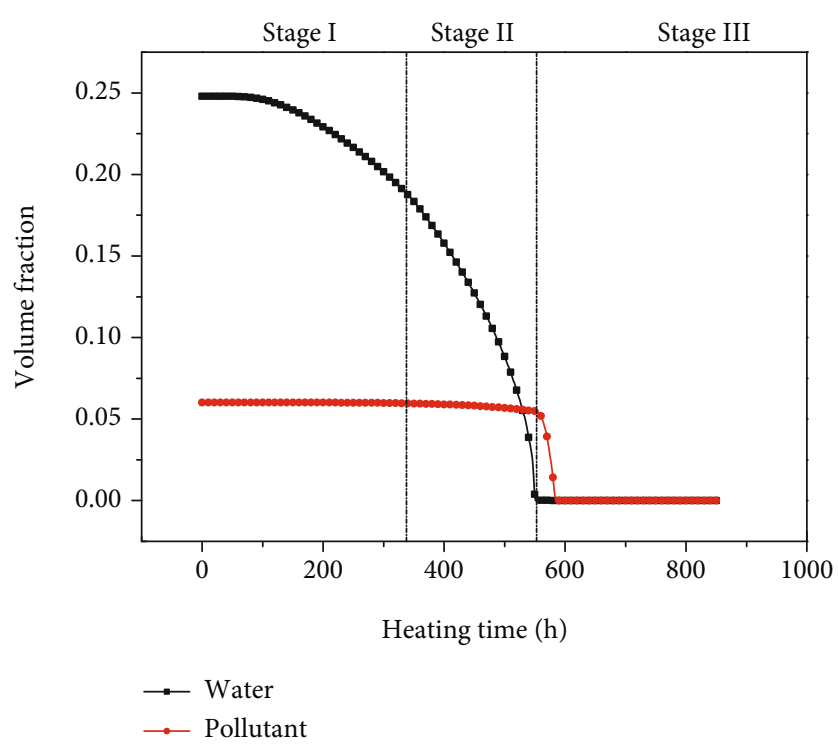

(a)

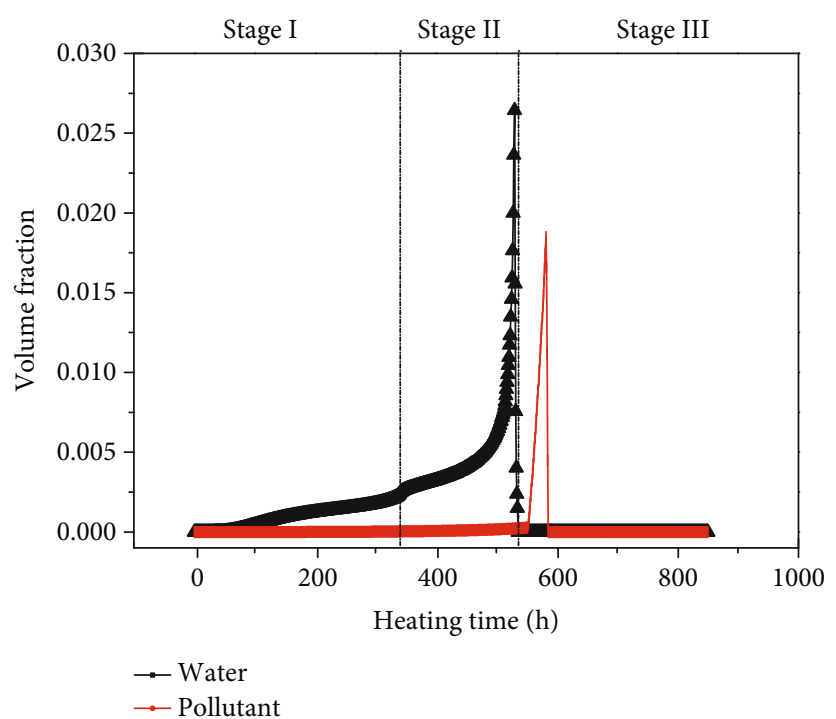

(b)

FIgURE 5: Volume fraction of toluene and water at the boundary soil (a) and in the off-gas (b).

energy-saving effect. It can be concluded that in practical engineering projects, the flue gas reflux ratio should be increased as much as possible to improve energy utilization. The energy utilization ratios of Cases 3.1, 3.2, and 3.3 increased by $3.22 \%, 11.27 \%$, and $19.36 \%$ in Stage I and by $4.90 \%, 15.23 \%$, and $25.55 \%$ in Stage III, respectively. The greater improvement obtained in Stage III results from the higher flue gas temperature and more recycled energy. Thus, it is more effective to apply the measure with a higher flue-gas reflux ratio in Stage III. However, it should be noted that the oxygen concentration may not meet the demand of complete combustion when the reflux ratio is increased to a certain level. This situation occurs mainly at the early stage of heat-returning mode because the flue gas temperature is lower and the required natural gas flow is relatively large to maintain the heating gas temperature.
Thus, in practice, it is advisable to reflux after the flue gas temperature rises to a certain level.

Further comparison of the natural gas consumption showed that the required natural gas consumption decreased with heating time in each case (Figure $7(\mathrm{~b})$ ). The main influencing factor was the flue gas temperature. The higher the flue gas temperature is, the more energy is reused, and the lower natural gas flow is required. An obvious difference in natural gas consumption was also observed with three reflux ratios of flue gas. The higher the flue gas reflux ratio is, the lower the natural gas flow is required. After heating for $585 \mathrm{~h}$, natural gas could be saved by $4.09 \%, 12.76 \%$, and $21.44 \%$ in Cases 3.1, 3.2, and 3.3, respectively. In a sense, the variation in the relative natural gas consumption in the heat-returning mode is mirror-symmetric with that of the 


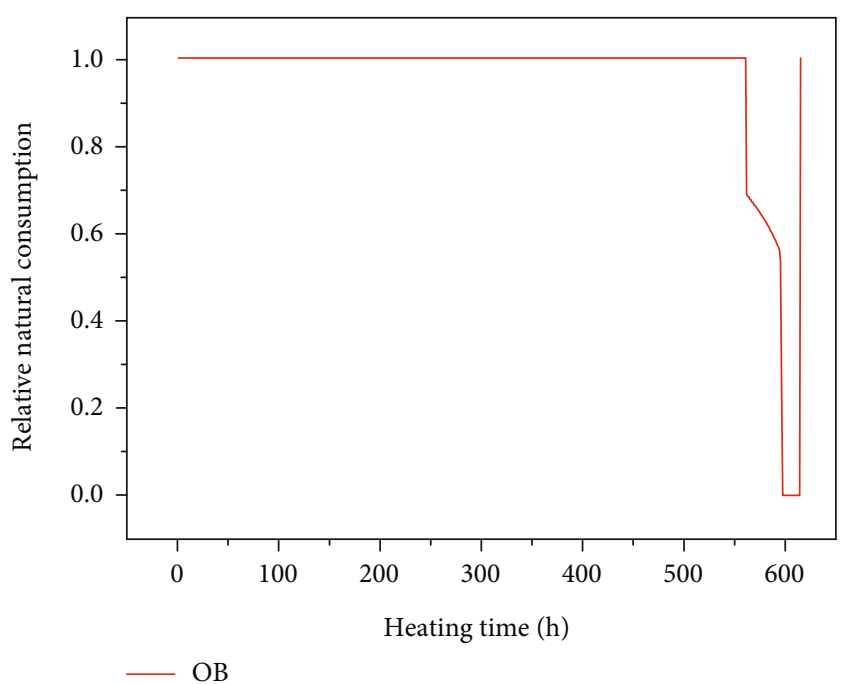

(a)

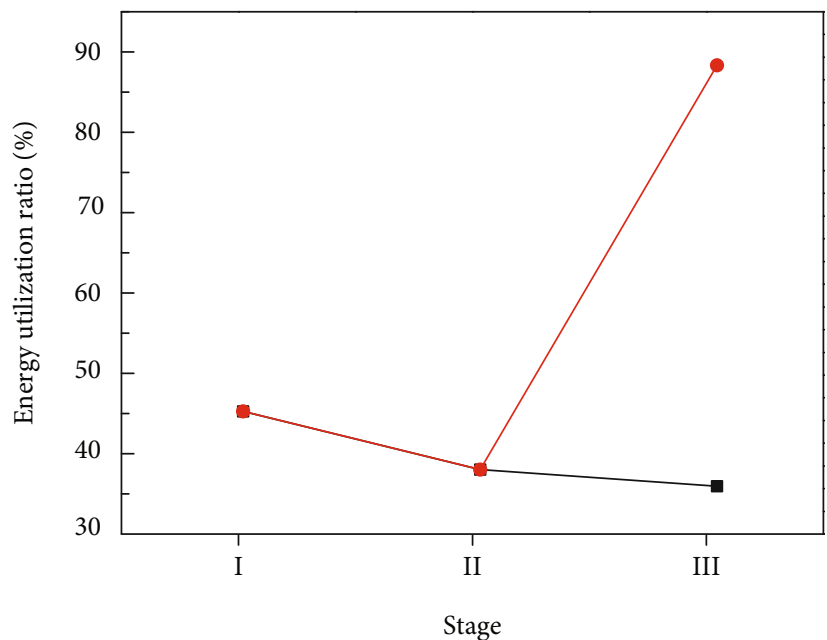

$\rightarrow-\mathrm{BM}$

(b)

FIGURE 6: Relative natural gas consumption $\left(G_{\mathrm{NmolOB}} / G_{\mathrm{NmolBM}}\right)$ through time (a) and energy utilization ratio (b) in the off-gas burn-back mode.

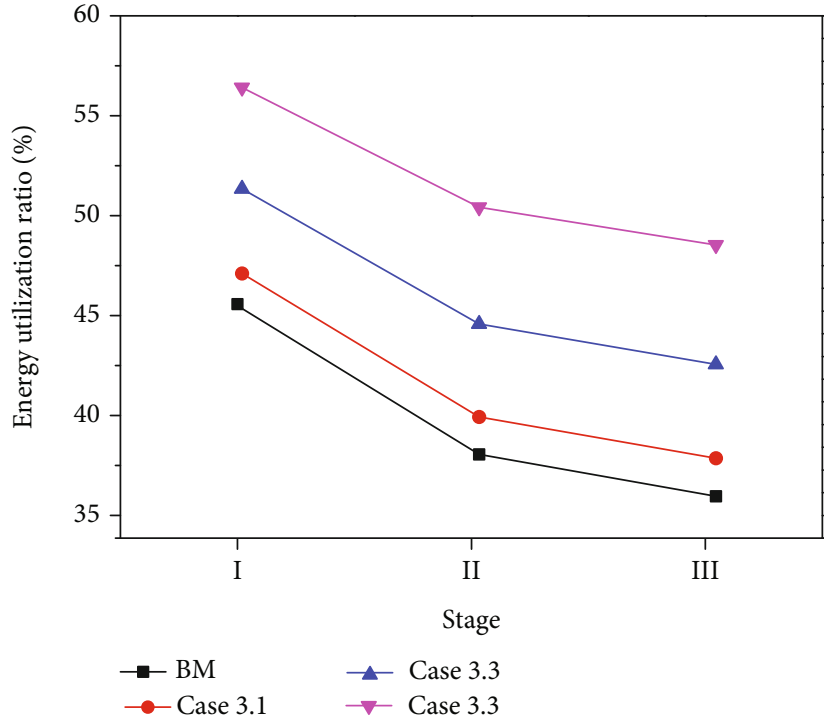

(a)

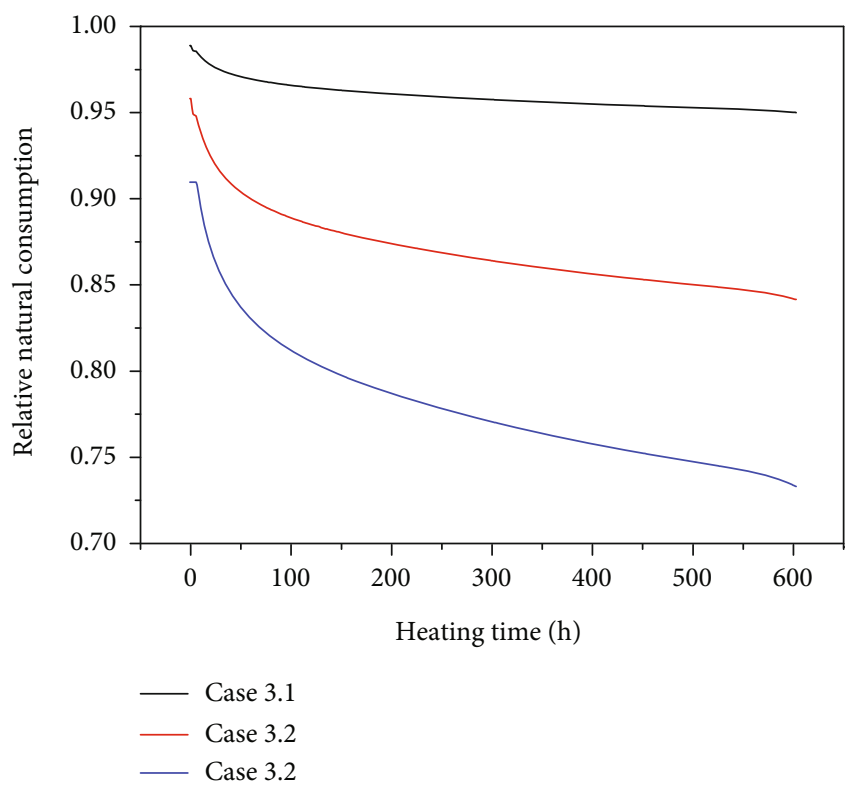

(b)

FIGURE 7: Energy utilization ratio (a) and relative natural gas consumption $\left(G_{\mathrm{NmolHR}} / G_{\mathrm{NmolBM}}\right)$ through time (b) in the heat-returning mode.

flue gas temperature, especially with a higher reflux ratio of the flue gas.

4.4. Energy Analysis of Air-Preheating Mode. In the airpreheating mode, the preheating ratios of combustion air in Case 4.1 and Case 4.2 were 0.5 and 1.0, respectively. It can be seen from Figure 8 that the trends of the energy utilization ratio in the air-preheating mode are the same as those in the basic method. The energy utilization ratios of both Case 4.1 and Case 4.2 were higher than that of Case $\mathrm{BM}$, and the energy utilization ratio increased with the increase in the preheating ratio. The promotion of the energy utilization ratio is more significant in Stage III than in Stages I and II, which is similar to the heat-returning mode. However, it can be found that the energy utilization ratios of the airpreheating mode were much lower than those obtained in the heat-returning mode at each stage. Even when the preheating ratio of the combustion air was set to 1.0 , which means 


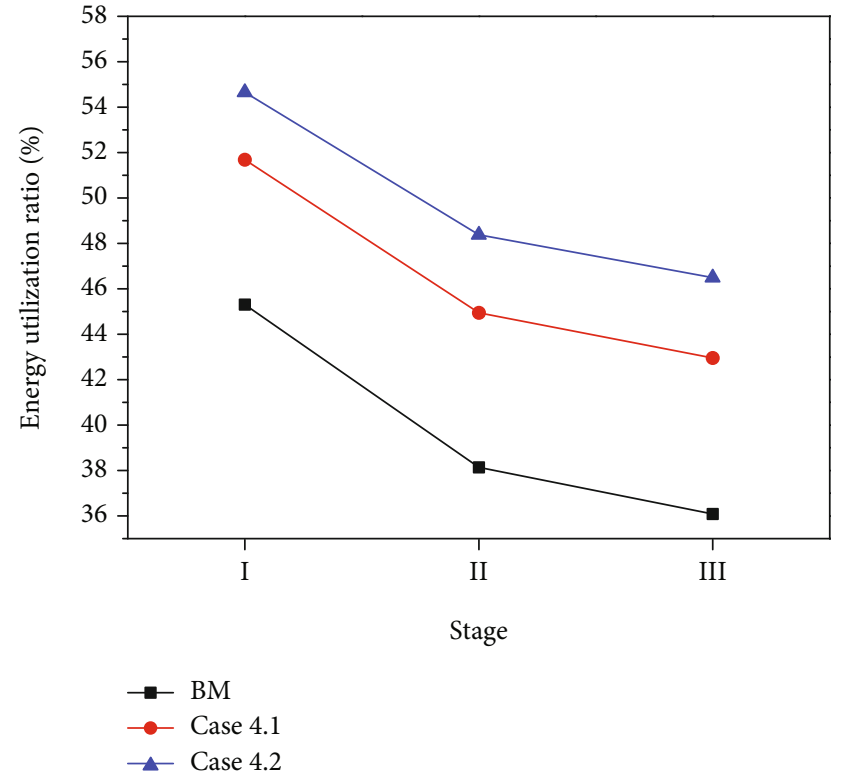

(a)

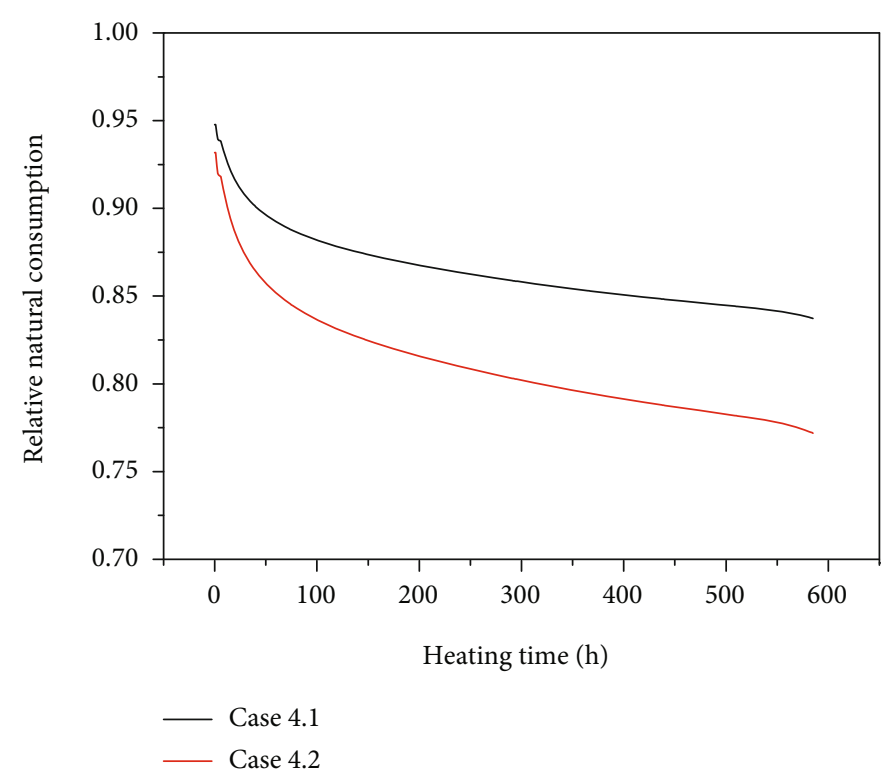

(b)

FIGURE 8: Energy utilization ratio (a) and relative natural gas consumption $\left(G_{\mathrm{NmolAP}} / G_{\mathrm{NmolBM}}\right)$ through time (b) in the air-preheating mode.

that all the combustion air was preheated before entering into the burner, and the energy utilization ratios increased by $10.40 \%$ in Stage III. This result is inferior to the effect of the heat-returning mode with a reflux ratio of 0.5 (25.55\%). This is because part of the heat in the flue gas is exchanged with the combustion air, while a large amount of heat cannot be recovered during the preheating process. After heating for $585 \mathrm{~h}$, natural gas just could be saved by $13.56 \%$ and $18.88 \%$ in Case 4.1 and Case 4.2, respectively. Among the three strategies, the best energy-saving effect was obtained via the heatreturning mode.

\section{Conclusions}

In this paper, three energy-saving strategies involving off-gas burn-back, heat-returning, and air-preheating for in situ gas thermal remediation were proposed, and their energy-saving effects were discussed through energy analysis. According to the simulation results of the mass and heat transfer model, as well as the burner models, the increase in temperature in the soil went through three stages: slow rising stage, plateau for water evaporation stage, and rapid rising stage. It took approximately $540 \mathrm{~h}$ to reach the target remediation temperature, which is the boiling point of toluene (pollutant) in our setting system. The time to the start of off-gas recycling at $540 \mathrm{~h}$ can be obtained from the trends of component concentration in soil and off-gas, as well as the terminal of remediation at $585 \mathrm{~h}$. In contrast to the basic method, adopting the off-gas burn-back mode can effectively save $3.37 \%$ of natural gas consumption when the volume fraction of toluene in soil was $6 \%$ and reduced the load of off-gas subsequent treatment. Under combustion air-preheating ratios of 0.5 and 1.0, natural gas can be saved by $13.56 \%$ and $18.88 \%$, respectively. Overall, the heat-returning mode was the most effective method, and $21.44 \%$ of the natural gas was saved when the reflux ratio was 0.5 . The higher the reflux ratio is, the better is the energy-saving effect. This study provided a modeling method for ISGTR system, which could obtain the continuous change of multiple parameters and avoid the difficulty of conducting tests through actual engineering. In addition, the results under different process conditions can offer a comprehensive reference for screening and applying energy-saving measures in actual projects.

\section{Data Availability}

The data that support the findings of this study are available from the corresponding author (yinyao@smedi.com) and first author (zhanghaijing@smedi.com) upon reasonable request.

\section{Conflicts of Interest}

The authors declare that there is no conflict of interest regarding the publication of this paper.

\section{Acknowledgments}

This study was supported by the Shanghai Rising-Star Program (No. 19QB1405300), the Science and Technology Commission of Shanghai Municipality (No. 19DZ1205205), the National Natural Science Foundation of China (No. 51806142), and the Shanghai Sailing Program (No. 18YF1418000). Also, all the authors of the following references are much appreciated.

\section{Supplementary Materials}

Supplementary material contained Table S1, which showed the input parameters for the physical model of heating unit in ISGTR system. (Supplementary Materials) 


\section{References}

[1] Y. Z. Liu, T. Wu, J. C. White, and D. H. Lin, “A new strategy using nanoscale zero-valent iron to simultaneously promote remediation and safe crop production in contaminated soil," Nature Nanotechnology, vol. 16, no. 2, pp. 197-205, 2021.

[2] S. Li, W. Jiao, H. Li et al., "Research and application progress of gas thermal desorption technology for the remediation of organic contaminated sites," Chinese Journal of Environmental. Engineering, vol. 13, no. 9, pp. 2037-2048, 2019.

[3] L. Abou Jaoude, G. Garau, N. Nassif, T. Darwish, and P. Castaldi, "Metal(loid)s immobilization in soils of Lebanon using municipal solid waste compost: microbial and biochemical impact," Applied Soil Ecology, vol. 143, pp. 134-143, 2019.

[4] United States Department of Defense, Design: In Situ Thermal Remediation; UFC 3-280-G05, United States Department of Defense, Washington, DC, USA, 2006

[5] P. L. O'Brien, T. M. DeSutter, F. X. M. Casey, E. Khan, and A. F. Wick, "Thermal remediation alters soil properties - a review," Journal of Environmental Management, vol. 206, pp. 826-835, 2018.

[6] S. Xin, In Situ Heat Treatment Coupled Remediation Technology and Equipment for Compound Organic Contaminated Sites; Nanjing Institute of Soil Science, Chinese Academy of Sciences, Shanghai, 2021.

[7] Y. Liu, X. Li, W. Zhang et al., "Effect and mechanisms of red mud catalyst on pyrolysis remediation of heavy hydrocarbons in weathered petroleum-contaminated soil," Journal of Environmental Chemical Engineering, vol. 9, no. 5, article 106090, 2021.

[8] J. Li, C. F. He, X. T. Cao, H. Sui, X. A. Li, and L. He, "Low temperature thermal desorption-chemical oxidation hybrid process for the remediation of organic contaminated model soil: a case study," Journal of Contaminant Hydrology, vol. 243, article 103908, 2021.

[9] F. Ma, C. Peng, D. Hou et al., "Citric acid facilitated thermal treatment: an innovative method for the remediation of mercury contaminated soil," Journal of Hazardous Materials, vol. 300, no. 30, pp. 546-552, 2015.

[10] T. F. Marcet, N. L. Cápiro, Y. Yang, F. E. Löffler, and K. D. Pennell, "Impacts of low-temperature thermal treatment on microbial detoxification of tetrachloroethene under continuous flow conditions," Water Research, vol. 145, no. 15, pp. 21-29, 2018.

[11] T. T. Li, Y. Z. Li, Z. Z. Zhai, E. H. Li, and T. Li, "Energy-saving strategies and their energy analysis and exergy analysis for in situ thermal remediation system of polluted-soil," Energies, vol. 12, no. 20, p. 4018, 2019.

[12] W. Wang, C. Li, Y. Z. Li, M. Yuan, and T. Li, "Numerical analysis of heat transfer performance of in situ thermal remediation of large polluted soil areas," Energies, vol. 12, no. 24, p. 4622, 2019.

[13] M. Kohout, A. P. Collier, and F. Štěpánek, "Mathematical modelling of solvent drying from a static particle bed," Chemical Engineering Science, vol. 61, no. 11, pp. 3674-3685, 2006.

[14] A. Michaud, R. Peczalski, and J. Andrieu, "Modeling of vacuum contact drying of crystalline powders packed beds," Chemical Engineering and Processing, vol. 47, no. 4, pp. 722730, 2008.

[15] I. M. Smallwood, Handbook of Organic Solvent Properties, Butterworth-Heinemann, 1996.
[16] Y. Nam, R. Ooka, and S. Hwang, "Development of a numerical model to predict heat exchange rates for a ground-source heat pump system," Energy and Buildings, vol. 40, no. 12, pp. 21332140, 2008.

[17] W. R. Gardner, D. Hillel, and Y. Benyamini, "Post-irrigation movement of soil water: 1. Redistribution," Water Resour. Research, vol. 6, no. 3, pp. 851-861, 1970.

[18] D. Bauer, W. Heidemann, and H. J. G. Diersch, “Transient 3D analysis of borehole heat exchanger modeling," Geothermics, vol. 40, no. 4, pp. 250-260, 2011.

[19] W. D. Shen and J. G. Tong, Engineering Thermodynamics, Higher Education Press, Beijing, 4th ed edition, 2007.

[20] Z. Z. Zhai, L. M. Yang, Y. Z. Li et al., "Fuzzy coordination control strategy and thermohydraulic dynamics modeling of a natural gas heating system for in situ soil thermal remediation," Entropy, vol. 21, no. 10, p. 971, 2019.

[21] China National Standardization Administration Committee, "GB/T 11062-1998 Natural gas -Calculation of calorific value, density, relative density and Wobbe indices from composition," China Standard Press, 1998. 